\title{
Appendiceal mucocele mimicking urolithiasis
}

\author{
Özgür Dandin¹, Ahmet Ziya Balta², İlker Sücüllü², Ergün Yücel², Ediz Tevfik Özgan , Șükrü Yıldırım
}

\section{ABSTRACT}

${ }^{1}$ Clinic of General Surgery, Bursa Military Hospital, Bursa, Turkey

${ }^{2}$ Clinic of General Surgery, Gülhane Military Academy Haydarpaşa Training Hospital, İstanbul, Turkey

${ }^{3}$ Clinic of General Surgery, Bursa State Hospital, Bursa, Turkey

${ }^{4}$ Department of Pathology, Bursa Military Hospital, Bursa, Turkey

Address for Correspondence Dr. Özgür Dandin

Clinic of General Surgery, Bursa Military Hospital, Bursa, Turkey Phone.: +905333892044 e-mail: dandinozgur@gmail.com

Received: 08.08.2011

Accepted: 29.12.2011

Online Available Date: 28.05.2013

CCopyright 2013 by Turkish Surgical Association
Appendiceal mucocele is a rare clinical condition that results from distension of the appendix lumen with mucus.

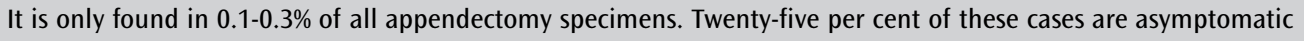
and are incidentally discovered either during surgery or upon radiological examination. The treatment of appendiceal mucocele is surgical, and while appendectomy is usually sufficient in some cases right hemicolectomy may be considered as a treatment option. Mucoceles are histologically subdivided into four types: retention cysts, mucosal hyperplasia, cystadenomas and cystadenocarcinomas. Herein, we present a case of appendiceal mucocele clinically mimicking urolithiasis in a 62-year-old female patient with a complaint of colicky right flank pain and a single episode of macroscopic hematuria. The patient's abdominal ultrasonography and abdominal CT scan showed a mass consistent with mucocele in the right lower quadrant of the abdomen. Colonoscopy gave the impression of a mass lesion exerting pressure from the outside. The patient was electively operated. Histopathological diagnosis was reported as mucinous cystadenoma. Appendiceal mucocele or mucinous cystadenomas are usually seen in patients undergoing surgery with a diagnosis of appendicitis but, as in our case, these lesions may rarely occur with a clinical picture that mimics urological disease.

Key Words: Mucocele, abdominal pain, hematuria, appendectomy

\section{INTRODUCTION}

Appendiceal mucocele is a rare clinical condition that results from distension of the appendix lumen with mucus $(1,2)$. It is only found in $0.1-0.3 \%$ of all appendectomy specimens (2-10). Twenty-five per cent of these cases are asymptomatic and are incidentally discovered either during surgery or upon radiological examination $(1,3,4)$. The most common finding in symptomatic patients is right lower quadrant pain mimicking acute appendicitis $(1,2,11)$. Other symptoms include intermittent colic-type pain, gastrointestinal bleeding, a palpable abdominal mass in the right lower quadrant, nausea, vomiting, weight loss and non-specific complaints like change in bowel habits (1, 2, 7, 9-11).

Urologic manifestations of appendiceal mucocele has been reported very rarely. Colic-type pain, hematuria, frequent urination accompanied by high fever and hydronephrosis are among urological findings $(1,7,12,13)$.

It is seen more frequently in women than men (M/F: 1/4), and usually in the 5th decade. The two most important methods of diagnosis are abdominal ultrasonography and tomography.

Its complications can be listed as torsion, intussusception, ureteral and intestinal obstruction, gastrointestinal bleeding, hematuria, and pseudomyxoma peritonei $(1,2,4-8,10-12)$.

Appendiceal mucocele has four sub-groups according to epithelial characteristics; retention cyst, mucosal hyperplasia, cystadenoma and cystadenocarcinoma $(2,3,7-10)$. Those with a transverse diameter smaller than $2 \mathrm{~cm}$ are usually simple retention cysts, whereas mucosal hyperplasia, cystadenoma and cystadenocarcinoma are usually larger than $2 \mathrm{~cm}(8)$.

Pseudomyxoma peritonei is the peritoneal dissemination of appendiceal mucocele due to spontaneous or iatrogenic perforation $(1,3-5,12)$. This is the most feared complication of a mucocele $(1,12)$.

Mucocele of the appendix may be simultaneously accompanied by solid organ tumors of the gastrointestinal tract, breast, kidney, or ovaries. Synchronous colon cancers were detected in $11-20 \%$ of patients with appendiceal mucocele (1). 


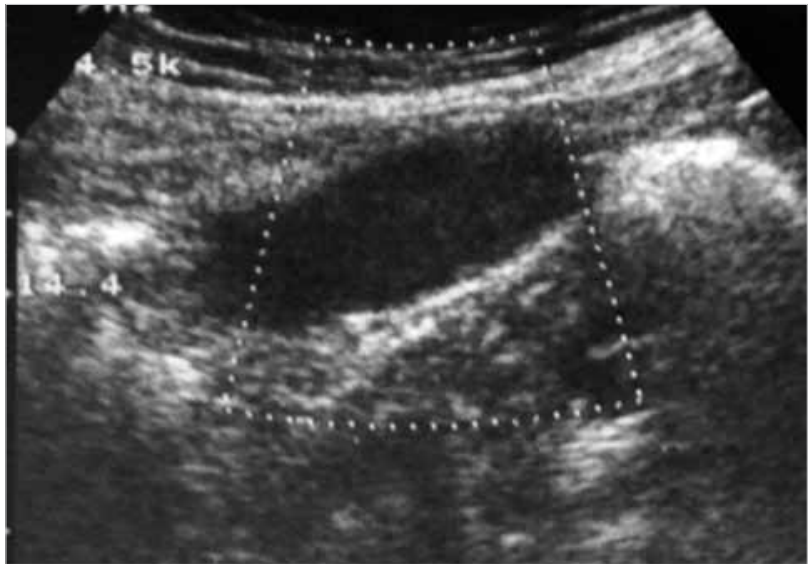

Figure 1. Abdominal ultrasonography, lesion consistent with mucocele

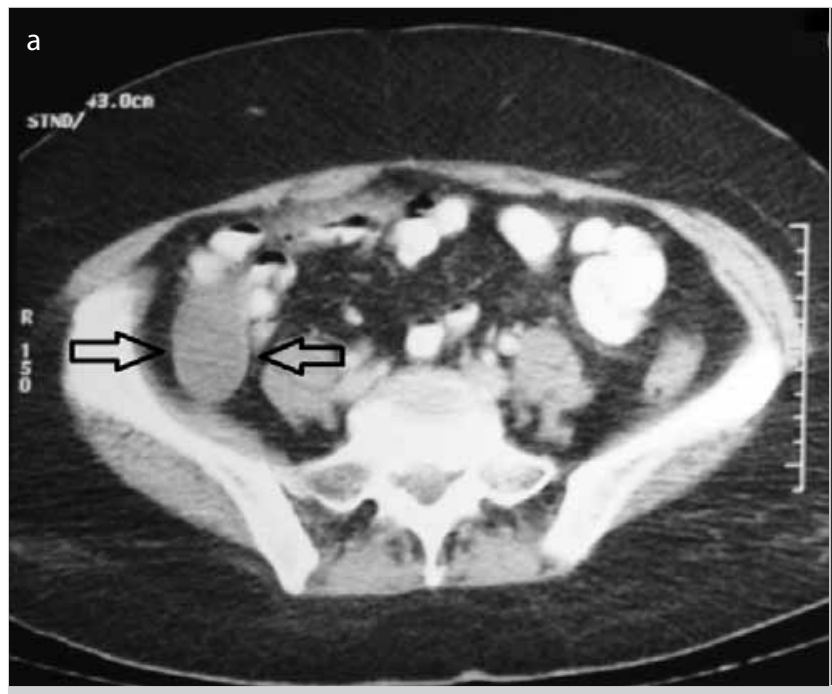

Figure 2. Abdominal CT view of the lesion

Herein, we present a case of appendiceal mucocele clinically mimicking urolithiasis with complaints of colicky flank pain and hematuria.

\section{CASE PRESENTATION}

A 62-year-old woman presented to the urology outpatient clinics with complaints of intermittent colicky right flank pain lasting for 2 months and macroscopic hematuria that occurred only once. The abdominal ultrasonography detected a 29x76 mm sized, hypo-anechoic lesion with distinct contours and boundaries located in the right lower quadrant. Doppler examination did not show vascularization. The lesion was interpreted as a mucocele and the patient was referred to our clinics (Figure 1).

The patient's laboratory values were all within normal range. Her past medical history was uneventful, and an abdominal computed tomography was planned to evaluate the differential diagnosis and the presence of additional pathologies. Abdominal computed tomography revealed a tubular-shaped cystic mass without any solid components, inferiorly extending from the level of right ileocecal valve, about $6.5 \times 3 \mathrm{~cm}$ in size, with a thin wall, having a density of about $20 \mathrm{HU}$ (Figure 2).

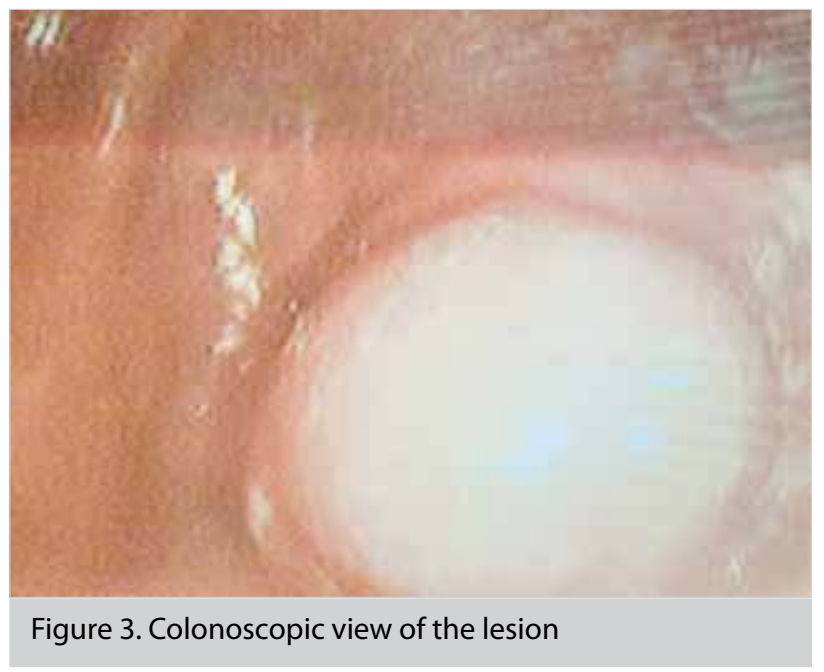

b

A colonoscopy was performed to rule out a possible colonic malignancy with a preliminary diagnosis of mucocele. The colonoscopy showed a polypoid lesion $30 \mathrm{~mm}$ in diameter, giving the impression of external pressure to the cecal lumen. Intraluminal pathology was not observed in the colon (Figure 3 ). Tumor markers including AFP, CEA, CA 19-9 were normal.

The patient was scheduled for surgery for definitive diagnosis and treatment. Elective exploration showed a $9 \times 4 \times 4 \mathrm{~cm}$ sized, smooth surfaced, cystic lesion filled with mucus located in the infero-medial aspect of cecum as the appendix, consistent with mucocele. The mass was broad-based, thus it was resected in a way to include the cecum wall by a stapler (Figure 4). She was uneventfully discharged on the seventh postoperative day.

The routine pathological examination of the specimen showed a cystic lesion that contains mesothelium on the outer side and mucin on the inner face, lined with single-layer columnar epithelium, with wall edema, including smooth muscle fibers, without multi-layers in the lining epithelium or nuclear atypia. It was reported as mucinous cystadenoma (Figure 5, 6). 


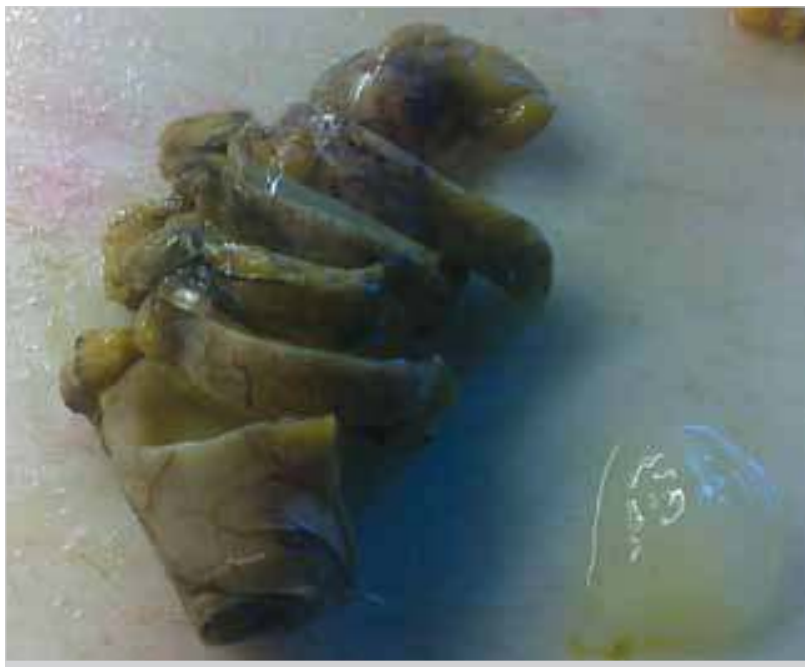

Figure 4. Macroscopic appearance of mucocele with its associated mucoid material

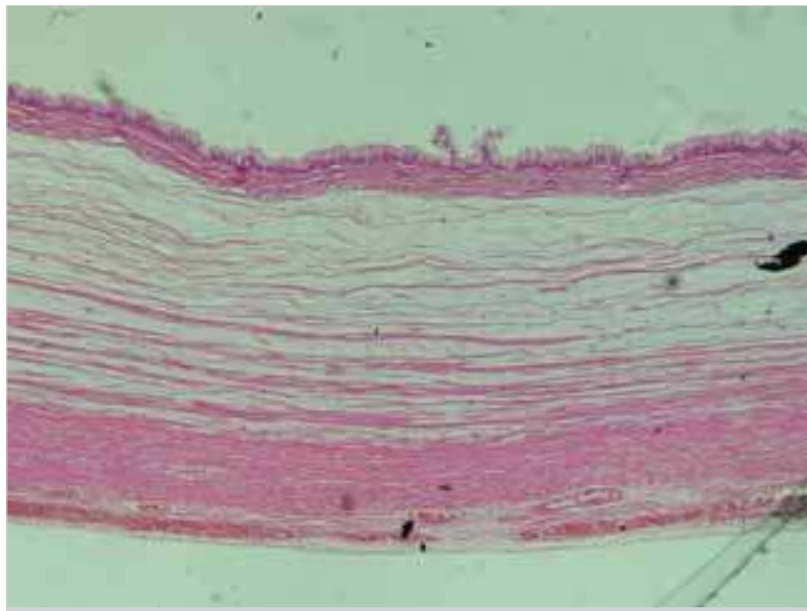

Figure 5. Histopathologic view of the lesion on hematoxylene eosin dye $x 40$

\section{DISCUSSION}

Urologic manifestations of appendiceal mucocele have rarely been reported $(7,11)$. Although rare, urological symptoms suggestive of urinary tract infection including colic-type pain, hematuria, frequent urination and high fever or hydronephrosis can be seen $(1,7)$. This finding is thought to result from compression of the appendix mucocele on the ureter (7).

The most common finding in symptomatic patients is right lower quadrant pain mimicking acute appendicitis $(1,2,11)$. Other symptoms include intermittent colic type pain caused by intussusception of the mucocele into the cecum, gastrointestinal bleeding, a palpable abdominal mass in the right lower quadrant (seen in $50 \%$ of cases), nausea, vomiting, weight loss and changes in bowel habit, although none of them are specific $(1,2,7,9-11)$.

There are four sub-groups according to the characteristics of the epithelium. Type I: is called simple or retention mucocele. It is caused by blockage of the lumen of the appendix and is usually caused by a fecalith. The luminal epithelium is normal and dilation is up to $1 \mathrm{~cm}$. Type II: It is the mucocele associated with hyper-plastic epithelium. Luminal dilation is not too

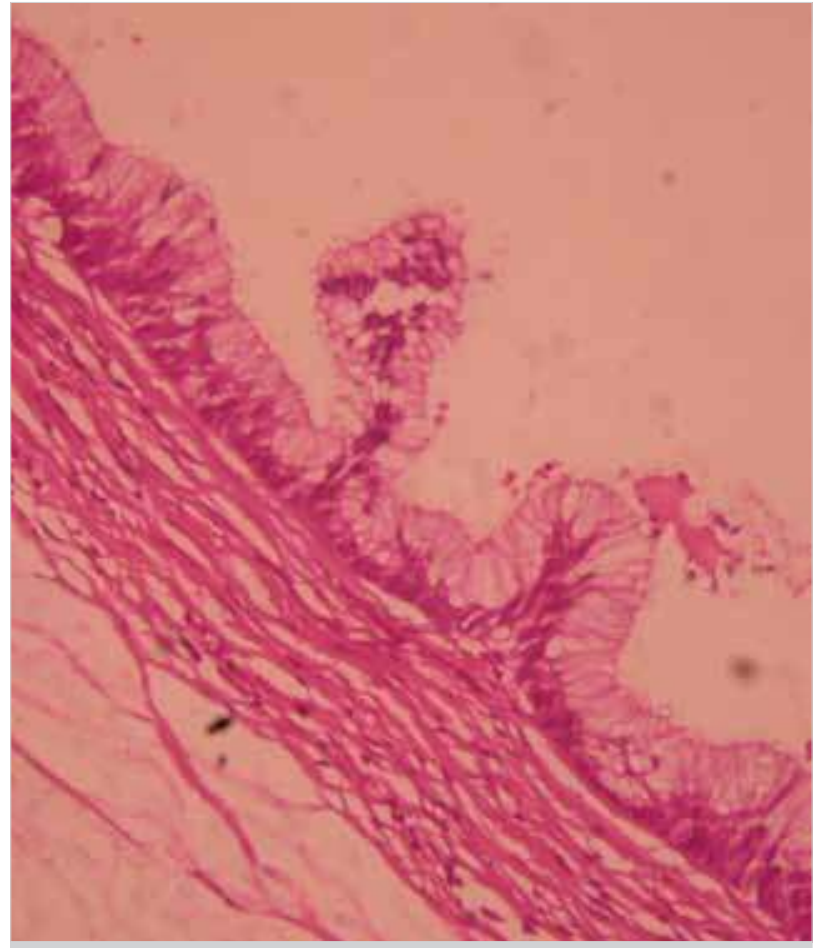

Figure 6. Histopathologic view of the lesion on hematoxylene eosin dye $\times 200$

extensive. They form 5 to $25 \%$ of mucoceles. Type III: They are benign mucoceles. They consists $63-84 \%$ of all mucoceles . Adenomatous villous epithelial changes are associated with different degrees of epithelial atypia. Luminal diameter can be dilated up to $6 \mathrm{~cm}$. Type IV are malignant mucinous cystadenoma and are observed at a rate of $11-20 \%$. They are distinguished from the other three groups with glandular stromal invasion and sometimes by presence of peritoneal epithelial cell implants. Lumen dilation is usually severe (3).

Pseudomyxoma peritonei is the peritoneal dissemination of appendiceal mucocele either due to spontaneous or iatrogenic perforation and is the most feared complication of a mucocele (1). Other complications are intussusception, ureteral and intestinal obstruction, gastrointestinal bleeding, and hematuria (4).

Perforation is observed in $20 \%$ of cystadenomas (3). In such cases, mucin can spread to the periappendicular area and the peritoneal cavity. However, mucous examination does not reveal neoplastic cells (3). Perforation is seen in about $6 \%$ of mucinous cystadenocarcinomas. Macroscopically cystadenoma and cystadenocarcinoma are indistinguishable. It can be noticed if neoplastic cells penetrate appendix wall and form peritoneal implants around the appendix (3).

The differential diagnosis of mucocele include right ovarian cyst, right hydrosalpinx, mesenteric cyst, duplication cyst, inflammatory bowel disease, complicated diverticulitis and chronic hematoma (2).

The two most important methods of diagnosis are ultrasound and computed tomography. Mucocele of the appendix is seen 
as an anechoic-hypoechoic cystic mass, containing internal echoes depending on the mucoid material, on ultrasound. Posterior acoustic strengthening is usually not expected since presence of mucin decreases the power of sound waves. Cyst wall is less apparent unlike the classic cyst image (2).

Typical signs of mucocele are a round or tubular cystic lesion at the appendix localization and without an inflammatory reaction, causing external compression on the cecal wall, presence of internal septation and sometimes mural calcification, and well encapsulated appearance on computed tomography (2). Barium enema shows a filling defect in the cecum (1). The 'volcano sign' on colonoscopy, a soft erythematous mass with a central crater, giving the impression of external compression to the cecum helps recognition (1). In our case, a polypoid, well-circumscribed lesion about $30 \mathrm{~mm}$ in diameter, protruding into the lumen of the cecum was found on colonoscopy. Fine-needle aspiration cytology is not recommended because of the risk of pseudomyxoma formation (1).

Appendectomy should be performed in cystadenoma or simple mucocele if the base of the appendix is healthy, and cecal resection should be performed in broad-based cystadenomas (1). Right hemicolectomy is recommended for malignant mucocele or cystadenocarcinoma (1). If the cystadenocarcinoma is located at the distal $2 / 3$ of the appendix, appendectomy can be sufficient (5). However, if propagation to the proximal $1 / 3$ is detected or if there are adhesions with the terminal ileum or cecum a right hemicolectomy is preferred (5).

Bilateral oophorectomy and omental resection should be added for treatment in the presence of spread to the ovaries and the greater omentum (5). Treatment of pseudomyxoma peritonei is excision of mucin deposits if localized (1).

Because of the probability of simultaneous solid tumors in the gastrointestinal tract, breast, kidney, and ovary with appendix mucocele a thorough surgical exploration should be performed (1). Colonic cancers were detected in $11-20 \%$ of patients with appendiceal mucocele (1). Tumor markers like AFP, CEA, and CA 19-9 should be evaluated as part of preoperative evaluation.

The 5 -year survival rate is $100 \%$ in benign mucoceles (1). This rate decreases to $45 \%$ in malignant forms (1). Especially if the underlying cause is mucinous cystadenocarcinoma, the 5 -year survival rate drops to $20 \%$ in pseudomyxoma peritonei related to it (6).

\section{CONCLUSION}

Mucocele of the appendix is a rarely seen, usually benign abdominal disease that can cause diagnostic confusion by mim- icking urolithiasis with complaints like hematuria and chronic colic-type flank pain, and may cause peritoneal pseudomyxoma if treated in a careless manner.

Informed Consent: Written informed consent was obtained from patients who participated in this case.

Peer-review: Externally peer-reviewed.

Author Contributions: Concept - I.S.; Design - I.S.; Data Collection and/ or Processing - Ö.D., E.T.Ö., Ş.Y.; Analysis and/or Interpretation - A.Z.B., E.Y.; Writer - Ö.D.

Conflict of Interest: No conflict of interest was declared by the authors.

Financial Disclosure: The authors declared that this study has received no financial support.

\section{REFERENCES}

1. Uluutku H, Demirbaş S, Kurt Y, Erenoğlu C, Akin L, Yildiz M. A case of giant appendiceal mucocele. Ulus Travma Acil Cerrahi Derg 2004; 10: 63-66.

2. Aslan $\mathrm{K}$, Nural M, Çebi H, Çalmaşur A, Danacı M. CT colonoscopy findings in appendiceal mucocele. J Exp Clin Med 2009; 26: 86-89. [CrossRef]

3. Özer M, Yiğit T, Uzar A, Mentes Ö, Eryılmaz M, Altınel Ö, ve ark. Laparoscopic resection of appendiceal mucınous cystadenoma: Case Report. Fırat Tıp Dergisi 2009; 14: 87-89.

4. Calişkan K, Yildirim S, Bal N, Nursal TZ, Akdur AC, Moray G. Mucinous cystadenoma of the appendix: a rare cause of acute abdomen. Ulus Travma Acil Cerrahi Derg 2008; 14: 303-307.

5. Bayram O, Kurukahvecioğlu O, Salman B. Secondary intestinal obstruction due to low-grade mucinous cystadenocarcinoma of the appendix. Ulus Travma Acil Cerrahi Derg 2004; 10: 67-70.

6. Yazıcı Z, Savcı G, Yalçın R, Yılmazlar T. Appendix mucocele. Tanısal ve Girişimsel Radyoloji 2001; 7: 564-567.

7. Nga K, Tanb C, Laib S, Chenc D, Chena W. Mucocele of the Appendix with Hematuria. Yale Journal of Biology and Medicine 742001 pp.9-12.

8. Khan MR, Ahmed R, Saleem T. Intricacies in the surgical management of appendiceal mucinous cystadenoma: a case report and review of the literature. J Med Case Rep 2010; 4: 129. [CrossRef]

9. Gortchev G, Tomov S, Dimitrov D, Nanev V, Betova T. Appendiceal mucocele presenting as a right adnexal mass: a case report. Obstet Gynecol Int 2010;2010. pii: 281053.

10. Mazure C, Plaza R, Carbajo M, Santoyo J. Letters to the Editor Giant appendiceal mucocele. Implications for diagnosis and therapeutics. Rev Esp Enferm Dig (Madrid) 2009; 101: 439-451.

11. García Lozano A, Vázquez Tarrago A, Castro García C, Richart Aznar J, Gómez Abril S, Martínez Abad M. [Mucocele of the appendix: Presentation of 31 cases]. Cir Esp 2010; 87: 108-112. [CrossRef]

12. Karakaya K, Barut F, Emre AU, Ucan HB, Cakmak GK, Irkorucu O, et al. Appendiceal mucocele: case reports and review of current literature. World J Gastroenterol 2008; 14: 2280-2283. [CrossRef]

13. Göksoy E, Geçioğlu A. Appendix mucocele: Case Report. Cerrahpaşa Tıp Fak Derg 1990; 21: 129-132. 